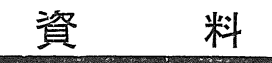

\title{
脂質命名に関する提案
}

\author{
J. Lipid Res., 8(5), 522 (1967)
}

脂質の命名法は有機化学者と生化学者の双方ともに関 心ある問題である。過去にも脂質の命名法を標準化しよ らといら試みはいくつかなされた。とくに米国科学アカ デミー (NAS) と米国学術会議 (NRC) の生化学命名法 連合小委員会 (委員長 W. E. M. Lands, 1962) があり, ほぼ同じころにドイッのグループによって，脂質の名称 についての提案 ${ }^{1}$ があった。

国際化学連合 (IUPAC) の生物学的命名法委員会と 国際大学連合 (IUB) の生化学関係雑誌編集者委員会は 1963 年に脂質命名法国際小委員会を H. Hirschmann を委員長として設けることを決定した。この小委員会は 討議を重放, 関心を有する協力者の助言をも得て, 前述 の二つの提案に含まれた資料のいくつ加に変更を加え た。IUPAC-IUB 小委員会は後に IUPAC-IUB 生化 学命名法連合小委員会 (CBN) となったが 1964 年に結 成された当時にはつぎの委員からなっていた。 H. Hirschman (委員長, 米国), A. Gottschalk (オーストラ リア), F.D. Gunstone (英国), M.L. Karnovsky (米 国), E. Klenk (ドイッ), W.E.M. Lands (米国), J. Polonovsky (フランス), L.L.M. van Deenen (オ ランダ), 委員間の討議は主として書面でなされ, その 草案は CBN の 1965 年 (パリ) および 1966 年 (Gothenburg）の会議とその両会議の間の通信で検討され た。ここに揭げた草案は以上の手続きを経て作られたも のであり, 関心を有する人々の参考のために発表されこ れが今秋，いくつかの生化学関係雑誌に揭載された。暫 定的な規約が各方面で討議され，脂質分野の化学者に受 け大れられて，すみやかに公式のものとなることが望ま れている。脂質命名法小委員会の直面したもっとも繁雑 な問題は立体異性体を区別することであった。glycerol の場合には少なくとも 4 種の異なった体系の命名法が提 案され，いろいろの人に採用されている。これらの提案 はそれぞれの長所，短所を有し，すべての目的に対し一 つでまにあらものはない。これが今回の新しい提案を生 んだ理由である。

脂質領域のすべての原子の立体配置については $\mathrm{E}$. Baer と H.O.L. Fischer の先駆者的な業績に基礎を置 き，もしその先取権を重要視するならば，かれらの提 案”を当然選ぶべきである。この方式は “ $\alpha$-monoglyceride は置換基の変更または移動の伴わない酸化によっ
て生成される glyceraldehyde と同じに分類されるとい ら条件を設け，われわれが $\alpha$-glycerophosphoric acid を monoglyceride と考えることに無理がないならこ れらを同じように論ずることができる。しかしこの命名 法の重大な限界はかれらの最初の論文に既に述べられて いる。それは $\alpha$-monoglyceride に対して示したと同様 の光学的分類は triglyceride では不可能である”。

この命名法は後に Bear と Buchnea ${ }^{3)}$ により初めの

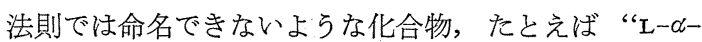
(dioleoyl) cephalin”などにまでも拡張されたが， triacylgycerol やアイソトープでラベルした glycerol にまで拡張することは提案されていない。この体系は

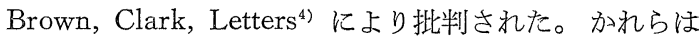
“ $几$ を 1 また 3 位置のいずれに決めるかによる混乱が 起こりうる”と述べ, Baddiley, Buchanan, Carss ${ }^{5)} に よ$ れば“天然に存在する L- $\alpha$-glycerophosphate (I) の 正しい名称は標準命名規約によれば D-glycerol 1phosphate (II) (L-glycerol 3-phosphate と同じ), と なる”という。一層慣用的な命名法でも同様に $\mathrm{D} / \mathrm{L} の$ 接磌辞を採用し，位置を示す数字を用い，置換した第一 アルコール基に小さい方の数字を与えるので Karnovsky, Hauser, Elwyn ${ }^{6}$ や Benson, Maruo ${ }^{7)}$ もれを用 いた。この方式はそのまま triacylglycerol やラベルし た glycerol などには適用できる。つごうの悪いことに

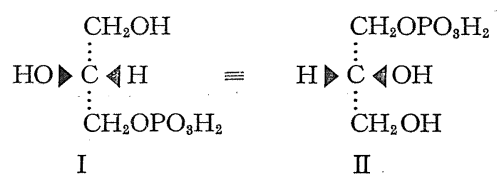

は同一物質に対し，位置を示寸接頭辞が互いに反対な， この二つの方式が共存することは混乱の大きな原因とな っており，どちらの約束に従らかを示す記号（それぞれ ギリシャ文字または数字によって位置を示す）によって のみ混乱を避けられる。

この困難さは $R / S$ 方式 [Cahn, Ingold, Prelog ${ }^{8}$ ] を採用すれば避けられる。 $R / S$ 方式は, その普遍的な性 質とあいほいさのないことで推奨されている。しかしな がら $R / S$ 方式でも $\mathrm{D} / \mathrm{L}$ 方式と同じく glycerol 誘導体 に適用したときには化学構造と生化学的作用との関係と いう点で不充分で，一般的方式とするには具合が悪い。 
例をあげると, glycerol 誘導体の化学的または生化学 的反応の大部分はエステルあるいはエーテル結合の生成 または開裂を伴うものである。これらの反応は glycerol の C-2 から出た四つの結合には何の影響もしないのに かかわらず $R / S$ または $\mathrm{D} / \mathrm{L}$ 方式の規約を用いると，立 体配置の接頭辞を絶えず書き替えなければならない。た とえば $(S)$-1，2-diacylglycerol(III) のリン酸化により $(R)$-phosphatidic acid(IV) が得られる。Baer-Fischer 方式によると D- $\alpha, \beta$-diacylglycerol (III) $\rightarrow$ diacyl-L- $\alpha$ -

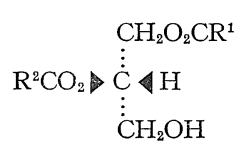

III glycerophosphoric acid (IV) と なる。慣用的な $\mathrm{D} / \mathrm{L}$ 方式では前駆 体 (III) は L-1,2-diacylglycerol で生成物は L-1,2-diacylglycerol 3-phosphate (IV) または D-2,3diacylglycerol 1-phosphate (V) $[\mathrm{III} \rightarrow(\mathrm{IV} \equiv \mathrm{V})]$ と書 く。もし IV の方をとれば，形はひっくりかえらないが アシル基の転位を記さなければならない。なぜならば, 生成物は D-glycerol 1-phosphate(II) と名ゔけられて いるからである。 $[(\mathrm{N} \equiv \mathrm{V}) \rightarrow(\mathrm{I} \equiv \mathrm{II})]$ 。さらに酵素

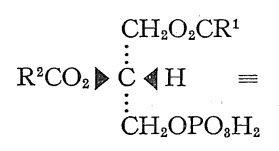

IV

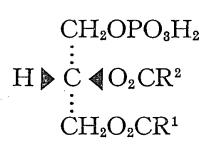

$\mathrm{V}$ phospholipase A (EC 3.1.1.4) は光学的に活性拉よび 不活性な 1,3-diacylglycero-2-phosphorylcholine (VI) を区別する [De Haas, Van Deenen ${ }^{9}$ ]。しかしこの立<smiles>COC[C@H](COC(C)=O)OP(=O)([O-])OCCN(C)C</smiles>

VI 体特異性は $\mathrm{D} / \mathrm{L}$ でも $R / S$ でも置換基の立体配置を表 現できない。もし triglycerideの第一アルコールに結 合している脂肪酸の分布が 任意でなく規則性があると いらことになれば，また別 の問題である。それ故慣用

的な立体配置の記号・( $/ \mathrm{L}$ ま また $R / S$ ) を使用するこ とは複合体混合物の不セイ性を表現するには不適当であ る。

その結果 glycerol 誘導体の立体構造は第四の方式 (立体特異性表示番号法, Hirschmann ${ }^{10)}$ ) によって表わ すと良い。この方式は出発物質である glycerol の二つ の第一アルコールは, 大部分の生化学的反応が関与す る ${ }^{11}$ 不セイ構造に基づく反応ではまったく等価ではない ため，命名法でもこれを区別すべきであるとする。1 3 は同一の第一アルコール基として相互に交換して用い てはならない。この方式ではどちらの第一アルコールを 1 とするかはつぎのとおりである。glycerol (VII) は図 に示す。もし Fischer 投影法で第二級の $\mathrm{OH}$ 基が $\mathrm{C}-2$

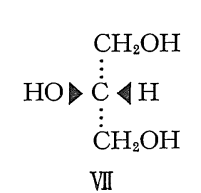

(1)

glycerol

( $s n$ 方式による番号は右側)
の左側に書かれたならば, C-2 の直上炭素原子を C-1 と呼び, 下を C-3 と呼ぶ。 この立体特異性表示番号法の 使用は“sn”なる接頭辞で化 合物名の語幹の前に書く。こ れは glycerol の二つの第一 アルコールを区別する命名法を使って置換された炭素原 子を指示するので, 誘導体の立体構造を記すのは矛盾の ない拡張と思われる。これを発展させたのは Stjerholm と Wood ${ }^{12)}$ でかれらは glycerol 3-phosphate を取り あげた [本命名法によれば “sn-glycerol 3-phosphate” と呼ぶべきである。(I) 参照)]。この方式では C-2の 四つの結合がそのまま残っているので化学式を倒置させ る必要がない。またある第一アルコール基はそれ自身ま たはほかの第一アルコールが $o$ 置換体になっても，番号 は変わらない。それ故, 配置の同一性は一見して明らか である。たとえば $s n$ 方式では上述のリン酸化は $1,2-$ diacyl-sn-glycerol (III) から 1,2-diacyl-sn-glycerol3-phosphate (IV) への変化となる。

同様にして phospholipase A 作用の特異性は, この 酵素が 2-sn-phosphatidylcholine (VI) の C-1 のエス テル結合に作用する（矢印で示した）として書ける。脂 肪酸残基のランダムでない分布は“ラット胫臟の triacyl -sn-glycerol において 1 位置は飽和脂肪酸の大部分を 含む” (Lands, Pieringer, Slakey, Zschocke ${ }^{13)}$ ) という ように表現される。

この新方法は Maquenne $\mathrm{e}^{14)}$ が inositol 類の立体配置 を示すために用いるので前例がない訳ではない。D と L または $R$ と $S$ を使用すると，対掌的関係を表わすに は明りょうではあるが，新しい方式を用いても $s n$-glycero-1-phosphoric acid (VIII) と sn-glycero-3-phos-

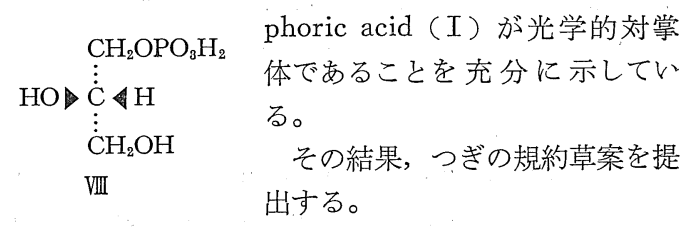

規 約 草 案

\section{Glycerol 含有脂質}

\section{A. 個々の化合物 (individual compounds)}

$1 \cdot 1$ glycerol のエステル，エーテルおよびそのほか $O$-誘導体の命名には炭水化合物命名規約 ${ }^{15)}$ の 10 および 11に従う。これらの規約はつぎのとおりである。(a) も しアルコール性 $\mathrm{OH}$ 基の水素原子がほかの 原子または 基で置換されたときは母体化合物の名称は誘導体名の語 幹として残しておき, 置換基を示寸接頭辞は直接語幹に 
つける。（b）エステルは母体化合物そのままの名称の後 に一字分空けて位置を指示する数字とハイフェンを置 き，酸から誘導された陰イオン基の名称をつぎに置く。 例

glycerol tristearate，または tristearoyl glycerol，または tri- $O$-stearoylglycerol;

1,3-benzylidenglycerol たは 1,3-O-benzylideneglycerol; glycerol 2-(dihydrogen phosphate) (これて対し "glycero2-phosphoric acid" 屯許される)

1.2 glycerol 誘導体を立体化学的に命名するために, glycerol の炭素原子に立体特異的に番号をつける。Fischer 投影法で炭素鎖を垂直になるように画き，第二級 $\mathrm{OH}$ 基を左側㯰いたとき，一番上にある炭素原子を C-1 とする。この番号を, 立体配置についてはなんら示 していない従来の方法に基づく番号とを区別するために 立体特異性番号表示 (stereospecifically numbered) の 頭文字 $s n$ なる接頭辞が用いられる。このことばは文章 の初めであってもイタリックの小文字で印刷され，八イ フェンで隔てて, glycerol を示す語が続く。“rac-” (racemo) なる接頭辞は, その生成物が両対掌体の等量 混合物であることを示し, “X-” はその物質の立体配置 が不明であるか，または区別していないことを示す。

例

$s n$-glycerol 3-(dihydrogen phosphate)または $s n$-glycero3-phosphoric acid (以前に汪 L- $\alpha$-glycerophosphoric acid(2) または D-glycerol 1-phosphate (7) とされていたものの立体 異性体;

rac-1-hexadecylglycerol;

$X$-glycerol 1,2-dipalmitate 3-stearate

\section{B. 種属名 (generic terms)}

1.3 “phosphoglyceride”なる語は glycerol 残基に 少なくとも一つの $O$-acyl, O-alkyl, O-alk-1'-en-1'-yl 基が付着している glycerophosphoric acid のすべての 誘導体を示す。もし phosphoglyceride の別のエステル 成分がわかっていれば，それを種属名の前に付ける。

例

choline phosphoglyceride

1.4 “phosphatidic acid” は glycerol の二つの $\mathrm{OH}$ 基がともに脂肪酸でエステル化されている glycerophosphoric acid の誘導体を示す。

1.5 “lecithin”は 1,2-diacyl-sn-glycero-3-phosphorylcholine に対し用いることは許されるが推奨はしな w。

1 -6 ほかの種属名は必要に応じて作られる。これら は個々の化合物（1 A を見よ）の名称にならってなさる べきであり，また acyl, alkyl, alkenyl(alk-1'-en-1'-yl すなわち $\mathrm{R}-\mathrm{CH}=\mathrm{CH}-$ ） のような接頭辞により glycerol の置換基の型を示すべきである。もしこれらの置換 基の性質が明らかでないときには，接頭辞 “radyl” が 用いられる。
例 1.4 より 1.6 項の例

phosphatidic ester;

1-alkenyl-2-acyl-sn-glycerophosphoric ester;

$O$-(diradylglycerophosphoryl)-L-serine ;

$O$-(1-acyl-sn-glycero-3-phosphoryl)ethanolamine ;

triacylglycerol;

diacyl-sn-glycero-3-phosphoryl-1'-sn-glycerol または 3$s n$-phosphatidyl-1'-sn-glycerol (IX)<smiles>[R]C[C@H](O)[C@H](CO[Po]([O-])(O)O)OC[C@H](CO)C([R4])=O</smiles>

3-sn-Phosphatidyl-1'-sn-glycerol

注）単に形式を一様に統一するためのみでなく, 慣用語の triglyceride と diglyceride ほ篇格に解釈すると, 充分にその 意味を伝えていないということがおもな理由で中性脂肪に対し triacylglycerol と diacylglycerol という語が選ばれた。

\section{Sphigolipids}

\section{A. 個々の化合物 (individual compounds)}

構造的に sphingosine に関連性ある多くの化合物の 発見は有機化合物命名法一般規則より一層簡明な名称を 採用して半体系的な命名法を発展させることが望ましく なった。

$2 \cdot 1$ 従来 dihydrosphingosine [2 D-aminoöctadecane -1,3 D-diol または D-erythro-2-aminoöctadecane-1, 3-diol または (2 $S, 3 R$ )-2-aminoöctadecane-1,3-diol] と呼ばれた化合物は sphinganine と呼ぶ。

$2 \cdot 2$ この名称は付加的置換または高級または低級同 族体を示す接頭辞をつける。同族体を示す接頭辞は long-chain base と同一炭素数をもつ炭化水素の体系的 名称 (IUPAC), 有機化合物命名法 ${ }^{16)}$, 規則 A-1) から “ne”を削ったものを用いなければならない。

$2 \cdot 3$ 置換体の配置は接頭辞 “ $D$ ”または “ $L$ ” [イタ リック大文字, Mills, Klyne $\left.{ }^{17)}\right]$ で示し，つぎに置換基 のついた炭素原子の位置を示す数字を置く。C-2 または C-3 における配置は sphinganine と異なった場合にの み，同様の方法で示される。接頭辞の $D$ または $L$ は， いかなる場合でも Fischer 投影法で C-1 を上にして炭 素鎖を縦になるように画いた場合，官能基の配列がそれ ぞれ右か左かにあることを示している。もし立体配置が 不明のときは接頭辞 “ $X-$-”用いる。ラセミ体の混合 物では“rac-”が接頭辞として用いられる。

注) long-chain base に対する半系統的命名法は, もしその 名称が置換基のみでなく，その立体配置をも意味するように選 
ばれれば，完全な系統的な命名法よりも短くなる。もし $D / L$ 方 式を用いれば通常出会う配置はみな同じ接頭辞を有するが, $R / S$ 方式では同じでない。すなわ占, sphingosine では C-3 は D または $R$ であり，以前 phytosphingosine と呼ばれた化合物

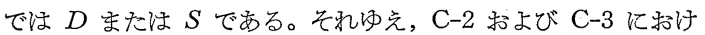
る配置の規則は $D / L$ 方式を用いて sphinganine と異なってい ることが明白な場合だけ特記すべきである。 $R / S$ 方式息を用い るときは，いつでもそれぞれ配置を明記した完全な体系的名称 を用いなければならない。

2.4 部分的不飽和化合物の名称は, 対応する 飽和化 合物に不飽和を意味する “ene”, “diene”, “yne”など をつけて用いる。二重結合は cis 型または幾何学的に不 明なことが，それぞれ “cis”または“X-”の記号を二 重結合の位置を示す数字の前につけることによって示さ れていない限り, trans 型を持つものと仮定する。

\section{例 $2 \cdot 1$ より $2 \cdot 4$ の項}

$4 D$-hydroxysphinganine[phytosphingosine];

$4 X$-hydroxy-2 $X, 3 X$-eicosasphinganine[Prostenik, Stanačev ${ }^{18)}$ による cerebring 塩基];

4-sphingenine[sphingosine];

cis-4-sphingenine[sphingosine の幾何異性体];

$2 L$-sphinganine[sphinganine $の \mathrm{C}-2$ epimer]

$2 \cdot 5$ 通俗名“sphingosine”はなお残されるが, sphingosine 似外の通俗名を用いる場合には, それぞれの論 文にその名称が本命名法または有機化学一般命名法によ って何と呼ばれるかを示さなければならない。

\section{B. 種属名 (generic terms)}

定義 “long-chain base”なる語は sphinganine 同 族体立体異性体およびこれら化合物の $\mathrm{OH}$ および不飽 和置換体を示す。

$2 \cdot 6$ つぎの種属名はそれぞれつぎの化合物に効して 用いてよい。

sphingolipid は long-chain base を含むす心゙ての脂 質;

glycosphingolipid は long-chain base および 1 個ま たはそれ以上の種を含む脂質；

ceramide [N-acyl long-chain base];

cerebroside [monoglycosylceramide];

ganglioside [neuraminic acid（3を見よ）を含む glycosphingolipid];

sphingomyelin [ceramide 1-phosphorylcholine]

$2 \cdot 7$ もしさらに構造の詳細を記すことができるなら ば，適当な接頭辞を用いる。これら接頭辞は化合物の置 換を示し，基幹名中に既に含まれる定義や修飾は示さな W。

例

1-O-D-galactosylceramide[galactocreobroside とはいわな (])

$\mathrm{N}$-acy-1-O-D-galactosyl-4-sphingenine;

1-triglycosylceramide;

oligoglycosylceramide

\section{Neuraminic Acid}

3.1 化合物 5-amino-3,5-dideoxy-D-glycero-D-galacto-nonulosonic acid は neuramininic acid (X) で

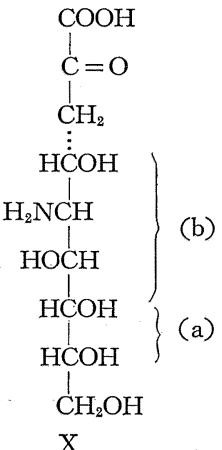

Neuraminic acid [5-amino-3, 5-dideoxy -D-glycero- $\mathrm{D}-$ galacto (a) (b) ある。 $3 \cdot 2$ "sialic acid" は $N$ acylneuraminic acid とそのエ ステルとアルコール性 $\mathrm{OH}$ 基 のほかの誘導体を示す。

$3 \cdot 3$ neuraminic acid また は sialic acid の $\mathrm{OH}$ 基を取 り除いたラジカルは，もし $\mathrm{OH}$ がカルボキシル基から取り除か れたのであれば，それぞれ neuraminoyl または sialoyl とい い, $\mathrm{OH}$ が環状構造のアノマー 炭素から除かれたのであれば， それぞれ neuraminosyl または sialosyl という。

\section{4 ほかの lipids 化合物}

$4 \cdot 1$ 脂肪酸と脂肪酸基は IUPAC の有機化合物命名 法 [(文献 19) 規則 C-4] により命名する。脂肪酸はカ ルボキシル基を常に C-1 として番号をつける。

注）ある種の天然脂肪酸の二重結合の位置のようなはっきり 決まったものでもこの方法によっては表現されないが，孷素鎖 の $\mathrm{C}$ 数を $n$ とし, 二重結合の位置を $(n-x)$ の形で表わせば, この番号付けの規則に違反せずに示すととができる。linoleic acid の二重結合の位置は $(n-9)$ と $(n-6)$ であるが $\omega 9, \omega 6$ で はない。

$4 \cdot 2$ 長鎖状アルコールとそのラジカルは系統的命名

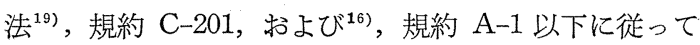
命名されるが，脂肪酸から由来する慣用名に習って命名 してはならない。

例

1-hexadecanol と 1-hexadecyl, palmityl alcohol $ゃ$ palmityl とほいわない。

$4 \cdot 3$ アミノ酸や糖のような脂質中のほかの構成分は 国際的に採用されている慣習に従って命名される。

4.4 1.4 中またはほかの引用した規約中に示されて いない慣用名や略名については，それぞれの論文中に明 示する。

\section{5 そのほかの種属名}

$5 \cdot 1$ “phospholipid”なる語はリン酸から誘導された。 ラジカルを含む脂質のすべてに対して用いられる。

5.2 “phosphoinositide” $は$ inositol とリン酸から 誘導されるラジカルを含む脂質のすべてに対して用いら れる。 
$5 \cdot 3$ これら規約中に示された種属名の 同義語は用い てならない。しかしそれ以外の語を脂質のほかのグルー プに対して適用するときは用いてよい。かかる非公式の 種属名は, それぞれの論文中に明示し, 接頭辞は語幹中 に既に含まれている構成分を示すよりは置換基を表わす ように組み立てられなければならない。（玉村貞夫訳） （昭和 42 年 12 月 20 日受理）

\section{文 献}

1) Biochem. Z., 235, 423 (1962)

2) E. Baer, H.O.L. Fischer, J, Biol. Chem., 128, 475 (1939)

3) E. Baer, D. Buchnea, J. Am. Chem. Soc, 81, 1758 (1959)

4) D.M. Brown, B.F.C. Clark, R. Letters, J. Chem. Soc. 1961,3774

5) J. Baddiley, J.G. Buchanan, B. Carss, J. Chem. Soc., 1957, 1869

6) M.L. Karnovsky, G. Hauser, D. Elwyn, J. Biol. Chem., 226, 881 (1957)
7) A.A. Benson, B. Maruo, Biochim. Biophys. Acta. 27, 189 (1958)

8) R.S. Cahn, C.K. Ingold, V. Prelog, Angew. Chem. Intern. Ed. Engl. 5, 385 (1966)

9) G.H. De Haas, L.L.M. Van Deenen. Biochim. Biophys. Acta. 84, 469 (1964)

10) H. Hirschmann, J. Biol. Chem., 235, 2762 (1960)

11) A.G. Ogston, Nature, 162, 963 (1948)

12) R. Stjernholm, H.G. Wood, J. Biol. Chem., 235, 2757 (1960)

13) W.E.M. Lands, R.A. Pieringer, P.M. Slakey, A. Zschocke, Lipids, 1, 444 (1966)

14) L. Maquenne "Les Sucres et Leur Principaux Dérivés", Gauthier-Villers, Paris (1900)

15) J. Org. Chem., 28, 281 (1963)

16) J. Am. Chem. Soc., 82, 5545 (1960)

17) J.A. Mills, W. Klyne, Progr. Stereochem., 1, 81 (1954)

18) M. Prostenik, N.Z. Stanačev, Ber., 91, 961 (1958)

19) IUPAC, Nomenclature of Organic Chemistry, Section C, Pure and Applied Chem., 11, Nos. 1-2 (1965)

“油化学”バックナンバー在庫のお知らせ

\begin{tabular}{|c|c|c|c|c|c|c|c|c|c|c|c|c|}
\hline 巻 (年) 号 & 1 & 2 & 3 & 4 & 5 & 6 & 7 & 8 & 9 & 10 & 11 & 12 \\
\hline $1(1952)$ & $200^{\text {円 }}$ & $200^{円}$ & $200^{円}$ & 200 円 & 一円 & —円 & -丹 & 一円 & 一问 & 一円 & 一円 & 一円 \\
\hline 2 (1953) & 200 & 200 & 200 & 200 & 200 & 200 & - & - & - & - & - & - \\
\hline $3(1954)$ & 欠 & 欠 & 欠 & 200 & 200 & 200 & - & - & - & - & - & - \\
\hline $4(1955)$ & 欠 & 欠 & 欠 & 200 & 200 & 200 & - & - & - & - & - & - \\
\hline $5(1956)$ & 200 & 200 & 200 & 200 & 200 & 200 & - & - & - & - & - & - \\
\hline $6(1957)$ & 200 & 200 & 200 & 200 & 200 & 200 & $350^{*}$ & - & - & - & - & - \\
\hline 7 (1958) & 欠 & 200 & 200 & 200 & 欠 & 200 & 200 & $300^{*}$ & - & - & - & - \\
\hline $8(1959)$ & 欠 & 欠 & 欠 & 欠 & 250 & $350 *$ & 250 & $350^{*}$ & 250 & 250 & 250 & $350 *$ \\
\hline $9(1960)$ & 欠 & 250 & 250 & 250 & $350^{*}$ & 250 & 350 & 250 & 250 & 350 & 250 & 250 \\
\hline $10(1961)$ & 350 & $350^{*}$ & 欠 & 350 & 250 & $350 *$ & 350 & 350 & 250 & 350 & 350 & 350 \\
\hline 11 (1962) & 200 & 300 & 300 & 300 & 300 & 300 & 300 & 300 & 300 & 300 & $350^{*}$ & 300 \\
\hline $12(1963)$ & 350 & 350 & 350 & 350 & 350 & 350 & 350 & $400^{*}$ & 350 & $400^{*}$ & 350 & 350 \\
\hline 13 (1964) & 350 & $400^{*}$ & 400 & 350 & 350 & 350 & 350 & 350 & 350 & 350 & 350 & 350 \\
\hline $14(1965)$ & 350 & 350 & 350 & 350 & 350 & 350 & 350 & $700^{*}$ & 350 & 350 & 350 & $700^{*}$ \\
\hline 15 (1966) & 500 & 500 & 500 & 欠 & 500 & 500 & 欠 & $1000 *$ & 500 & 500 & 500 & 500 \\
\hline $16(1967)$ & 500 & 500 & 500 & 500 & $1500 *$ & 500 & 500 & 500 & 500 & 500 & 500 & 500 \\
\hline
\end{tabular}

* 印は特集号です

バックナンバーが上記のように在庫しております。ご入用の方は代金，送料（部数，地域によって料金が異な りますので事務局へお問合せください）を添えてお申込みください。 